Article

\title{
Properties of Arsenic-Doped ZnTe Thin Films as a Back Contact for CdTe Solar Cells
}

\author{
Ochai Oklobia *, Giray Kartopu and Stuart J. C. Irvine \\ Centre for Solar Energy Research, College of Engineering, Swansea University, OpTIC Centre, St. Asaph \\ Business Park LL17 0JD, UK; giray.kartopu@swansea.ac.uk (G.K.); s.j.c.irvine@swansea.ac.uk (S.J.C.I.) \\ * Correspondence: ochai.oklobia@swansea.ac.uk
}

Received: 30 September 2019; Accepted: 7 November 2019; Published: 10 November 2019

\begin{abstract}
As-doped polycrystalline ZnTe layers grown by metalorganic chemical vapor deposition (MOCVD) have been investigated as a back contact for CdTe solar cells. While undoped ZnTe films were essentially insulating, the doped layers showed significant rise in conductivity with increasing As concentration. High p-type carrier densities up $4.5 \times 10^{18} \mathrm{~cm}^{-3}$ was measured by the Hall-effect in heavily doped ZnTe:As films, displaying electrical properties comparable to epitaxial ZnTe single crystalline thin films in the literature. Device incorporation with as-deposited ZnTe:As yielded lower photovoltaic $(\mathrm{PV})$ performance compared to reference devices, due to losses in the open-circuit potential $\left(\mathrm{V}_{\mathrm{OC}}\right)$ and fill factor $(\mathrm{FF})$ related to reducing p-type doping density $\left(\mathrm{N}_{\mathrm{A}}\right)$ in the absorber layer. Some minor recovery observed in absorber doping following a Cl-free post-ZnTe:As deposition anneal in hydrogen at $420{ }^{\circ} \mathrm{C}$ contributed to a slight improvement in $\mathrm{V}_{\mathrm{OC}}$ and $N_{\mathrm{A}}$, highlighting the significance of back contact activation. A mild $\mathrm{CdCl}_{2}$ activation process on the $\mathrm{ZnTe:As} \mathrm{back}$ contact layer via a sacrificial CdS cap layer has been assessed to suppress $\mathrm{Zn}$ losses, which occur in the case of standard $\mathrm{CdCl}_{2}$ anneal treatments (CHT) via formation of volatile $\mathrm{ZnCl}_{2}$. The CdS sacrificial cap was effective in minimising the $\mathrm{Zn}$ loss. Compared to untreated and non-capped, mild CHT processed ZnTe:As back contacted devices, mild CHT with a CdS barrier showed the highest recovery in absorber doping and an $\sim 10 \mathrm{mV}$ gain in $\mathrm{V}_{\mathrm{OC}}$, with the best cell efficiency approaching the baseline devices.
\end{abstract}

Keywords: ZnTe:As back contact; CdTe; thin films; solar cells; metalorganic chemical vapor deposition (MOCVD)

\section{Introduction}

Record efficiencies as high as $22.1 \%$ have been reported for cadmium telluride (CdTe) solar cells [1], making it one of the fastest growing and promising thin film technologies. CdTe continues to attract increasing interest in academia and industry as it is ideal for very high performance photovoltaic (PV) applications, mainly due to a high absorption coefficient $>10^{4} \mathrm{~cm}^{-1}$, a bandgap of $1.45 \mathrm{eV}$ and low-cost manufacturing attributes. Even with such reported high efficiencies, much work is still needed to close the gap towards the theoretical maximum of 30\% [2].

Insertion of a wide band gap material between the CdTe absorber and metal contact has demonstrated promise for efficiency improvement [3]. This approach overcomes the problem of the Schottky barrier formed at $\mathrm{CdTe} /$ metal interface, for available metal contacts [4]. Another approach is incorporating a p+ region near the CdTe back surface [5]. In the former; the use of p-type ZnTe thin film is considered to be a good example. With a zincblende (cubic) structure and a bandgap of $\sim 2.26 \mathrm{eV}$, ZnTe has negligible valence band discontinuity with respect to CdTe (which would not impede hole transport), and a large conduction band offset, which can be beneficial for electron back reflection to 
CdTe and hence minimize minority carrier recombination related losses at the interface to the metal back contact [3,6]. Additionally, very high p-type doping concentrations achievable with ZnTe can provide a low resistance Ohmic contact to the metal electrode. Cu-doped ZnTe back contact to CdTe have been credited with improvement in device efficiency [7], however $\mathrm{Cu}$ diffusion and subsequent long-term device stability remains an issue [8]. As an alternative to $\mathrm{ZnTe}: \mathrm{Cu}$, group V (N, As)-doped $\mathrm{ZnTe}$ can be used as a back contact. Specifically ZnTe:N has been recognised as a suitable back contact for CdTe thin film solar cells [9], also providing improved device stability, compared to ZnTe:Cu [10].

In our baseline CdTe thin film solar cell structure (Figure 1a), according to a superstrate configuration, a heavily As-doped $\left(\sim 10^{19}\right.$ atoms $\left.\mathrm{cm}^{-3}\right)$ CdTe cap layer, denoted by the p+-CdTe back contact layer (BCL) was found to lower the device's series resistance [5], resulting in efficiencies as high as $13.0 \%$ being achieved. However, dopability with CdTe is challenging, as a recent study by Kartopu et al [11] has shown As doping of polycrystalline CdTe with an upper limit of $\sim 3 \times 10^{16} \mathrm{~cm}^{-3}$. Nevertheless, p-type doping of ZnTe to very high levels is achievable in comparison, where doping concentrations as high as $1 \times 10^{18} \mathrm{~cm}^{-3}$ for in-situ doped ZnTe:As have been reported [12,13]. With such doping levels, $\mathrm{p}-\mathrm{ZnTe} \mathrm{BCL}$ is expected to further reduce back contact resistance, and therefore contribute to improving the device's series resistance. In this study, we sought to substitute the heavily doped (p+-CdTe) cap layer with a p+-ZnTe BCL, which has comparably higher doping efficiency, by using metalorganic chemical vapor deposition (MOCVD) to grow As-doped ZnTe with good conductivity. We investigated properties of the ZnTe:As BCL to CdTe thin film solar cells and reported post-deposition treatments, for cell performance improvement. Activation of the $\mathrm{ZnTe} B C L$ using conventional $\mathrm{CdCl}_{2}$ deposition followed by heat treatment (CHT) is known to be challenging due to $\mathrm{Zn}$ loss via the formation of highly volatile $\mathrm{ZnCl}_{2}$ during the process $[14,15]$. Therefore we also investigated and report on the development of an activation process by assessing a thin layer of MOCVD grown sacrificial CdS layer on ZnTe:As to control the BCL activation step. In addition to a slight performance improvement, we also showed evidence of the barrier function of $\mathrm{CdS}$ in minimizing $\mathrm{Zn}$ loss.

\section{Materials and Methods}

Solar cells in this study were fabricated in the superstrate configuration in a horizontal atmospheric pressure (AP)-MOCVD reactor (Cryogenic Vacuum Technology, Milton Keynes, UK), using hydrogen as a carrier gas. The $C d T e$ baseline cell structure was fabricated by depositing a window layer $\left(\mathrm{Cd}_{1-\mathrm{x}} \mathrm{Zn}_{\mathrm{x}} \mathrm{S}\right)$ on indium tin oxide (ITO)-coated boro-aluminosilicate glass substrates $(4-8 \Omega / \square)$, followed by the CdTe absorber, comprising a $\sim 2.6 \mu \mathrm{m}$ As-doped p-CdTe layer terminated with a more heavily doped, p+-CdTe $(\sim 300 \mathrm{~nm})$ back contact layer. Further experimental details can be found elsewhere [16]. Cell activation was achieved via CHT, performed by depositing a thick layer $(\sim 3.0 \mu \mathrm{m})$ of $\mathrm{CdCl}_{2}$ thin film at $200{ }^{\circ} \mathrm{C}$, then anneal for $10 \mathrm{~min}$ at $420{ }^{\circ} \mathrm{C}$ under hydrogen ambient. After cooling to room temperature, the structure was taken out of the reactor and excess $\mathrm{CdCl}_{2}$ rinsed with deionized (DI) water, and a secondary post-deposition annealing was carried out at $170{ }^{\circ} \mathrm{C}$, for $90 \mathrm{~min}$ in air ambient. Finally, the solar cell was completed by evaporation of Au metal back contacts through a shadow mask. Dimethylcadmium (DMCd), diisopropyltelluride (DIPTe), diethylzinc (DEZn), and tertiarybutylchloride ( $\mathrm{tBuCl}$ ) were used as the metalorganic precursors for $\mathrm{Cd}, \mathrm{Te}, \mathrm{Zn}$, and $\mathrm{Cl}$, respectively, whilst tris(dimethylamino)arsenic (tDMAAs) was used for the As dopant. The schematic layout of the baseline cell and ZnTe-contacted structures in this work are illustrated in Figure 1.

Before incorporating ZnTe:As BCL in the CdTe cell structure, reference single layers of the $\mathrm{ZnTe}$ thin films were first grown at $370{ }^{\circ} \mathrm{C}$ on uncoated boro-aluminosilicate glass substrates using MOCVD, whilst controlling its p-type property by varying the tDMAAs flows between 0 and $10 \mathrm{sccm}$, corresponding to partial pressures of $0-4.73 \times 10^{-6} \mathrm{~atm}$. The thicknesses of the reference thin films was measured to be $\sim 500 \mathrm{~nm}$. Transmittance and Hall-effect measurements were carried out to determine the optical and electronic properties of the corresponding ZnTe:As thin films. The heavily doped ZnTe achieved with $10 \mathrm{sccm}$ of tDMAAs flow was subsequently incorporated into the p-CdTe absorber, as the back contact layer. Prior to ZnTe:As BCL deposition on to the p-CdTe back surface, the absorber base 
structure was activated similarly to the baseline structure, cooled to room temperature, excess $\mathrm{CdCl}_{2}$ rinsed off with DI water and returned to the MOCVD reactor within $24 \mathrm{~h}$. Figure $1 \mathrm{~b}$ shows the cell structure grown by omitting the p+-CdTe layer and then finished with ZnTe:As deposition. To improve ZnTe:As BCL crystallinity, annealing under flowing $\mathrm{H}_{2}$ gas at $420{ }^{\circ} \mathrm{C}$ for $10 \mathrm{~min}$ (i.e., $\mathrm{Cl}$-free $\mathrm{H}_{2}$ anneal), was performed subsequently. In determining the optimal annealing conditions for the ZnTe:As $\mathrm{BCL}$, the $\mathrm{Cl}$-free $\mathrm{H}_{2}$ anneals were performed on different Glass/ITO/Cd ${ }_{1-\mathrm{x}} \mathrm{Zn}_{\mathrm{x}} \mathrm{S} / \mathrm{p}-\mathrm{CdTe}-\mathrm{CHT} / \mathrm{ZnTe}$ :As samples for times ranging between 0 and $30 \mathrm{~min}\left(\right.$ at $420^{\circ} \mathrm{C}$ ), and also at temperatures ranging from 420 to $450{ }^{\circ} \mathrm{C}$ (for $10 \mathrm{~min}$ ).

To assess the ZnTe:As back contact on $\mathrm{p}$-CdTe thin film solar cell performance, a control device (i.e., a Glass/ITO/Cd $\mathrm{Cd}_{1-\mathrm{x}} \mathrm{Zn}_{\mathrm{x}} \mathrm{S} / \mathrm{p}-\mathrm{CdTe}-\mathrm{CHT}$ structure, without the $\mathrm{p}+-\mathrm{CdTe} \mathrm{BCL}$ ), in addition to our baseline cell structure, was also fabricated.

For the ZnTe:As BCL activation, we first performed a wet chloride treatment, by immersing a Glass/ITO/Cd $\mathrm{Cd}_{1-\mathrm{x}} \mathrm{Zn}_{\mathrm{x}} \mathrm{S} / \mathrm{p}-\mathrm{CdTe}-\mathrm{CHT} / \mathrm{ZnTe}$ :As sample in a $10 \% \mathrm{ZnCl}_{2} /$ methanol solution for $2 \mathrm{~min}$, left it to dry in air before transferring into the MOCVD reactor for a subsequent $\mathrm{H}_{2}$ anneal. The $\mathrm{ZnCl}_{2}$ wet treatment here was assessed as an alternative to our standard CHT treatment (for CdTe absorbers) and according to literature is expected to minimise or avoid $\mathrm{Zn}$ loss from the ZnTe:As BCL [14]. On another batch of Glass/ITO/Cd $\mathrm{Cd}_{1-\mathrm{x}} \mathrm{Zn}_{\mathrm{x}} \mathrm{S} / \mathrm{p}-\mathrm{CdTe}-\mathrm{CHT} / \mathrm{ZnTe}$ :As samples, we also investigated the development of a relatively mild CHT activation step, for the ZnTe:As BCL, using a thin CdS cap layer [15] to minimise $\mathrm{Zn}$ loss during the process. After ZnTe:As BCL deposition on p-CdTe in the MOCVD reactor, and performing a Cl-free $\mathrm{H}_{2}$ anneal, the $\mathrm{CdS}(\sim 80 \mathrm{~nm})$ cap layer and a relatively thin layer of $\mathrm{CdCl}_{2}$ were sequentially grown. The resulting structure (Glass/ITO/Cd $\mathrm{C}_{1-\mathrm{x}} \mathrm{Zn}_{\mathrm{x}} \mathrm{S} / \mathrm{p}-\mathrm{CdTe}-\mathrm{CHT} / \mathrm{ZnTe}: \mathrm{As} / \mathrm{CdS} / \mathrm{CdCl}_{2}$ ) was then annealed at $420^{\circ} \mathrm{C}$ for only $3 \mathrm{~min}$ in $\mathrm{H}_{2}$. Upon cooling down to room temperature, samples were removed from the MOCVD reactor, with excess $\mathrm{CdCl}_{2}$ rinsed off and the CdS layer selectively removed by etching in a $15 \%$ aqueous $\mathrm{HCl}$ acid solution and rinsed again with $\mathrm{DI}$ water to remove any residual products. Three different samples were processed: a reference (without the mild CHT or CdS layer, i.e. Glass/ITO/Cd $\mathrm{Cd}_{1-\mathrm{x}} \mathrm{Zn}_{\mathrm{x}} \mathrm{S} / \mathrm{p}$-CdTe-CHT/ZnTe:As) and two other samples with the mild CHT but

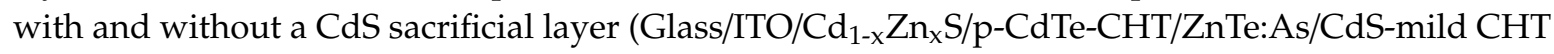
and Glass/ITO/Cd ${ }_{1-x} \mathrm{Zn}_{x} \mathrm{~S} / \mathrm{p}$-CdTe-CHT/ZnTe:As/-mild CHT). Prior to device completion by Au contact evaporation, all ZnTe:As back contacted device structures were subjected to a standard secondary annealing in ambient air at $170{ }^{\circ} \mathrm{C}$ for $90 \mathrm{~min}$.

AM 1.5 J-V measurements were performed using an Abet Technologies Ltd. (Milford, CT, USA) solar simulator with the light power density calibrated using a GaAs reference cell. C-V characteristics were measured using a Solartron Impedance Analyzer (Ametek Scientific Instruments, Farnborough, UK). External quantum efficiency (EQE) measurements were carried out using a Bentham spectral response system (Bentham Instruments Ltd., Berkshire, UK). The system response was corrected by scanning the output of a c-Si reference detector. Energy dispersive X-ray spectroscopy (EDX), to determine elemental compositions, was carried out using a Hitachi TM3000 (Hitachi Ltd., Tokyo, Japan) table-top scanning electron microscope (SEM). X-ray diffraction (XRD) measurements were obtained from a D8 Discover (Bruker, Karlsruhe, Germany) diffractometer. Cl depth profiling was performed via secondary-ion mass spectroscopy (SIMS) with a Cameca IMS-4f instrument (LSA Ltd., Leicestershire, UK) with a Cs+ ion source operating with $10 \mathrm{keV}$ energy and $20 \mathrm{nA}$ current. Samples for SIMS were prepared by first cleaving $\sim 1 \times 1 \mathrm{~cm}^{2}$ specimens, and back surface subsequently etched in a $0.2 \%$ bromine solution in methanol $(\mathrm{BrMeOH})$ for $5 \mathrm{~s}$, rinsed with methanol and dried with a $\mathrm{N}_{2}$ gun. 
(a)

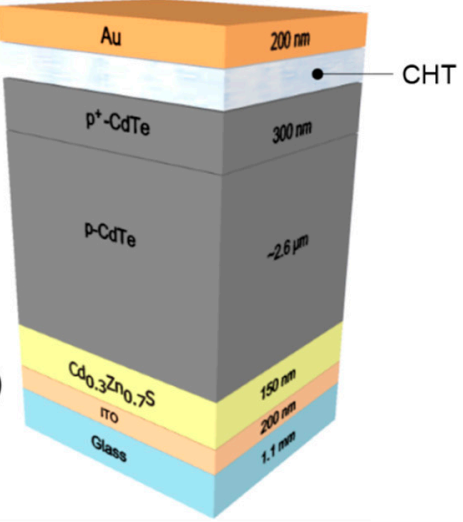

(c)

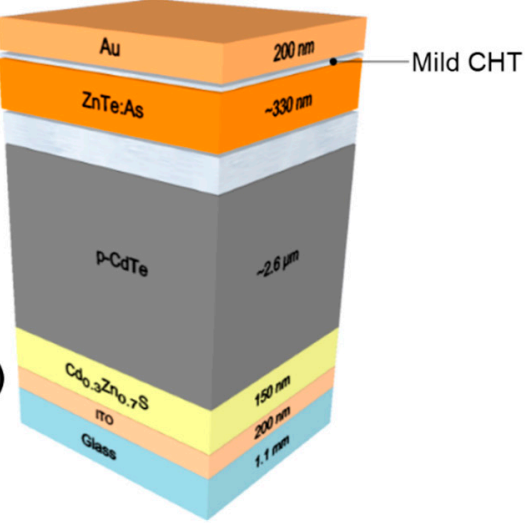

(b)

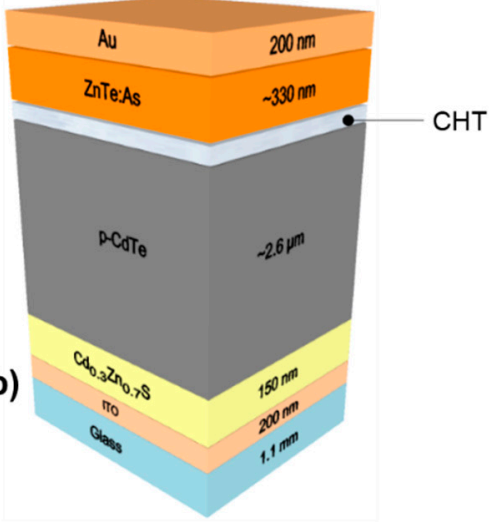

(d)

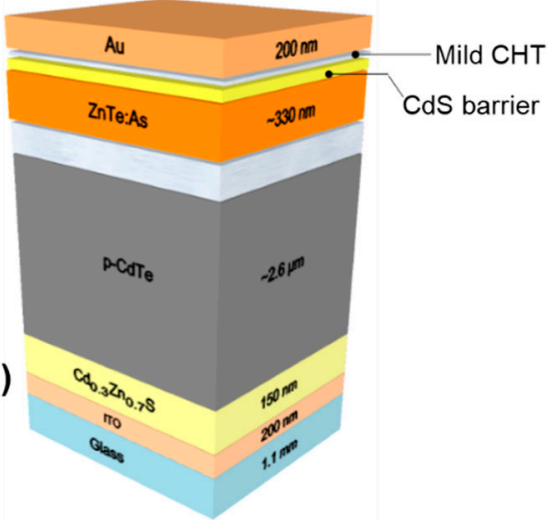

Figure 1. Schematic of (a) baseline CdTe cell; (b) ZnTe:As back-contacted CdTe cell, and (c) ZnTe:As back contacted cell with mild Cl-anneal without a CdS sacrificial layer (d) ZnTe:As back contacted cell with mild $\mathrm{Cl}$-anneal using a CdS sacrificial layer (not to scale).

\section{Results}

\subsection{Properties of As-Doped Polycrystalline ( $p x)$ ZnTe Thin Films by MOCVD}

Electrical properties of MOCVD grown reference px ZnTe thin films on boro-aluminosilicate glass substrate with different As flows, determined by Hall-effect measurements, are summarized in Table 1. Each thin film sample was annealed in air at $170{ }^{\circ} \mathrm{C}$ for 90 min prior to Hall-effect measurements, as this was found to be beneficial for improving the dopant activation [5]. The bandgap values in Table 1 were estimated from Tauc plots.

Table 1. Electrical parameters from Hall-effect measurements on ZnTe:As thin film samples deposited on uncoated glass substrate with different amounts of As.

\begin{tabular}{cccccc}
\hline $\begin{array}{c}\text { As } \\
(\mathbf{s c c m})\end{array}$ & $\begin{array}{c}\text { Bandgap } \\
\mathbf{( e V )}\end{array}$ & $\begin{array}{c}\text { Bulk concentration } \\
\left(\mathbf{c m}^{-3}\right)\end{array}$ & $\begin{array}{c}\text { Mobility } \\
\left(\mathbf{c m}^{\mathbf{2}} \mathbf{/ V} \cdot \mathbf{s}\right)\end{array}$ & $\begin{array}{c}\text { Resistivity } \\
\mathbf{( \Omega \cdot c m})\end{array}$ & $\begin{array}{c}\text { Conductivity } \\
(\mathbf{S} / \mathbf{c m})\end{array}$ \\
\hline 0 & 2.23 & - & - & - & - \\
1 & 2.24 & - & - & $2.93 \times 10^{4}$ & $3.41 \times 10^{-5}$ \\
3 & 2.21 & $5.33 \times 10^{17}$ & $7.54 \times 10^{-2}$ & $1.55 \times 10^{2}$ & $6.45 \times 10^{-3}$ \\
5 & 2.20 & $1.11 \times 10^{18}$ & $2.74 \times 10^{-1}$ & $2.14 \times 10^{1}$ & $4.68 \times 10^{-2}$ \\
10 & 2.19 & $4.50 \times 10^{18}$ & $8.48 \times 10^{-1}$ & $1.63 \times 10^{0}$ & $6.14 \times 10^{-1}$ \\
\hline
\end{tabular}

Due to the highly resistive nature of the undoped ZnTe film, no reliable data was obtained by the Hall-effect measurements. When an As flow of $3 \mathrm{sccm}$ was used during the ZnTe growth, a p-type conductive film with a bulk concentration of $5.33 \times 10^{17} \mathrm{~cm}^{-3}$ was obtained. The resistivity however was noted to be high. Bulk concentration increases with increasing As flow to $4.50 \times 10^{18} \mathrm{~cm}^{-3}$ for 
$10 \mathrm{sccm}$, with a corresponding decrease in the resistivity (Figure 2). Such low resistivities with high doping densities are expected to be beneficial to forming low-resistance Ohmic contacts in CdTe thin film solar cells. Becker et al. successfully demonstrated the utilization of a $20 \mathrm{~nm}$ ZnTe:As (epitaxial) MOCVD thin film, displaying $2 \times 10^{18} \mathrm{~cm}^{-3}$ p-type carrier density, as the hole collecting back contact within a single crystalline $\mathrm{CdTe} / \mathrm{CdMgTe}$ double heterostructure [17].

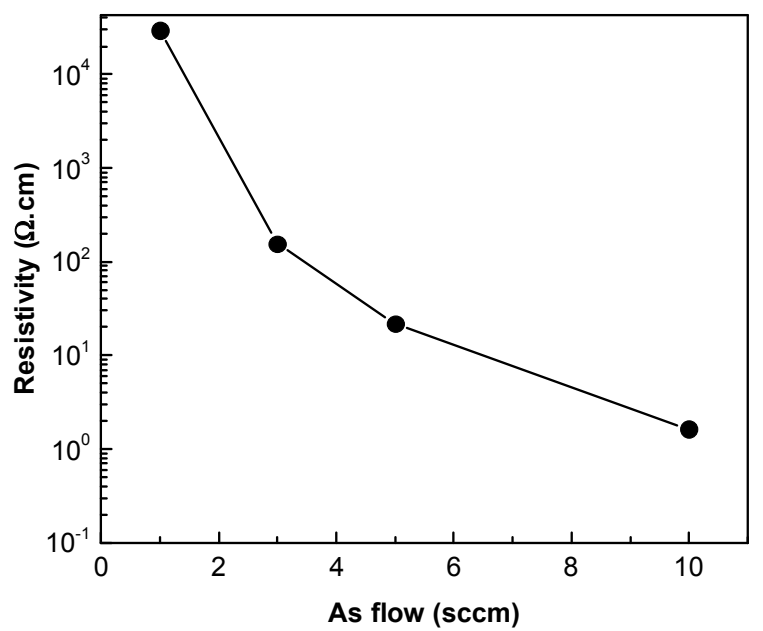

Figure 2. Resistivity change in As-doped px ZnTe reference thin films with As precursor flows.

Optical properties investigated by measuring the transmittance spectra (see Supplementary Materials Figure S1) of the reference sample px ZnTe thin films showed absorption increase with As flow. The thin films were deposited to $\sim 500 \mathrm{~nm}$ thickness. The corresponding optical bandgaps estimated from Tauc plots (Table 1) indicated a bandgap value of $2.23 \mathrm{eV}$ for the undoped px ZnTe and this decreased slightly to $2.13 \mathrm{eV}$ with the highest As doping used $(10 \mathrm{sccm})$.

To probe the impact of As doping on the microstructure, we compared the X-ray diffraction pattern of undoped and highly doped px ZnTe (see Figure S2). Three peaks can be seen at $2 \theta$ angles of $25.3^{\circ}, 49.5^{\circ}$, and $52.0^{\circ}$, corresponding to preferential (111) and comparatively weaker (311) and (222) planes, in the undoped ZnTe thin film $[3,8,14]$. The (111) peak intensity was observed to reduce with doping (i.e., with $10 \mathrm{sccm}$ of As) and the $\mathrm{ZnTe}$ (222) was absent, along with the emergence of additional peaks, indicating some disorder forming. The new peak at $38.3^{\circ}$ corresponds to Te (102), suggesting As substitution in Te sites and in general recrystallisation of the ZnTe, whilst the other peaks at $29.6^{\circ}$, $44.1^{\circ}$, and $64.4^{\circ}$ (denoted by symbol $\mathbf{v}$ ) does not appear to correspond to any ZnTe phases. No shift in the (111) diffraction was noticed, which contrasts with reported XRD data for ZnTe:N [18], where a peak shift in (111) was induced by nitrogen doping, attributed to the embedding of nitrogen atoms in interstitial sites, resulting in films with decreased lattice parameter due to compressive stress.

\subsection{Device Incorporation of ZnTe:As to CdTe Thin Film Solar Cells}

A comparison of the illuminated J-V curves of as-deposited ZnTe:As back contacted CdTe thin film solar cell, baseline and control devices are shown in Figure 3a. The growth parameters for the ZnTe:As BCL incorporated into the p-CdTe structure were chosen based on the property results from reference ZnTe:As thin films (see Table 1). Dopant precursor flow was kept fixed at $10 \mathrm{sccm}$ and the BCL film thickness was about $\sim 330 \mathrm{~nm}$ (Figure 1b). Note that cells defined by the Au contacts on the ZnTe:As back contacted devices had to be isolated by scribing before J-V measurements, as ZnTe:As BCL was found to exhibit high lateral conductivity which contributed to current collection beyond the actual defined cell area. 

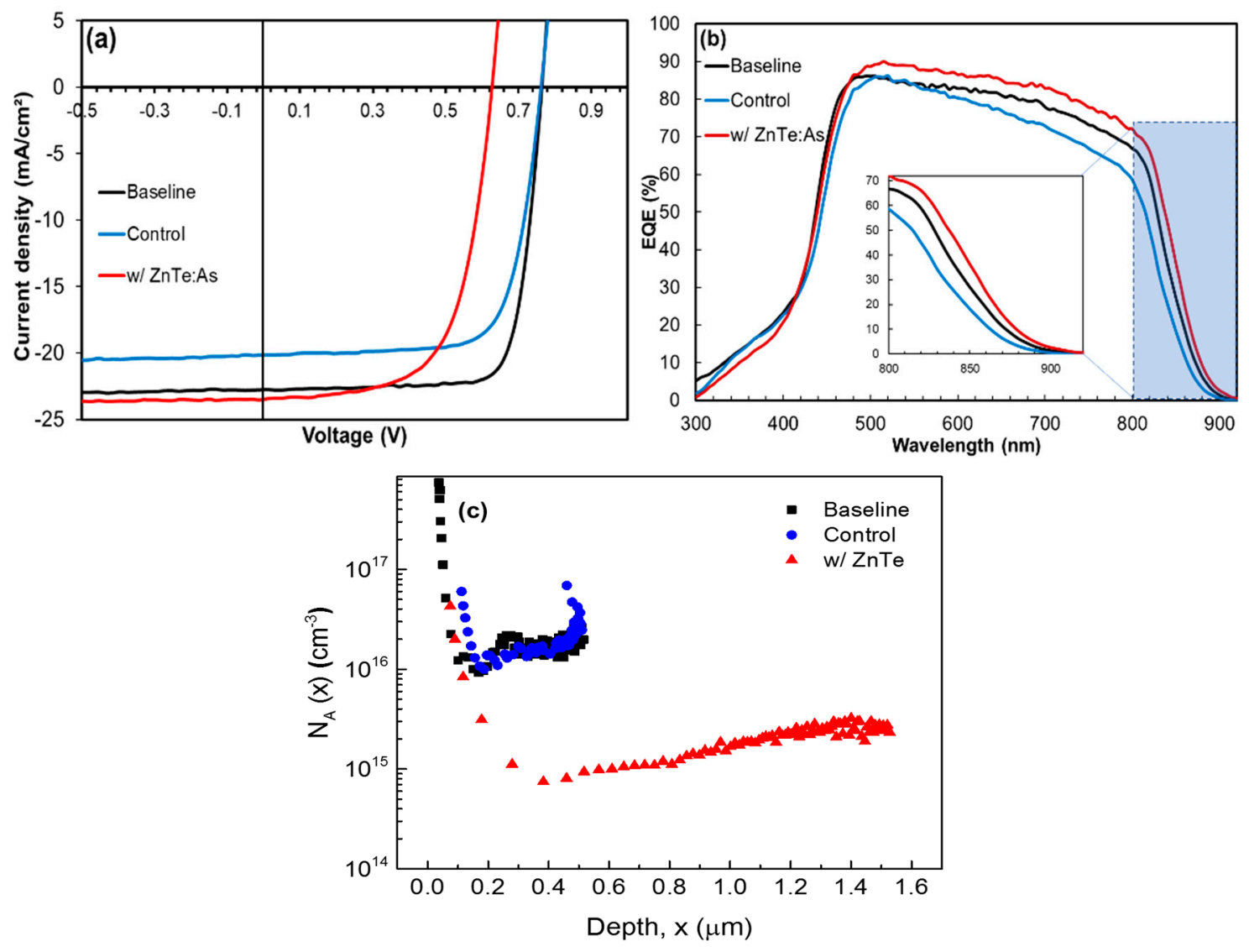

Figure 3. (a) Illuminated J-V curves (b) external quantum efficiency (EQE) spectra and (c) acceptor concentration profiles for: baseline, control, and ZnTe:As (with NO post-deposition treatment) back contacted devices.

From Figure $3 \mathrm{a}$, open-circuit voltage $\left(\mathrm{V}_{\mathrm{OC}}\right)$, short circuit current density $\left(\mathrm{J}_{S C}\right)$, and fill factor $(\mathrm{FF})$ of $0.748 \mathrm{~V}, 20.2 \mathrm{~mA} / \mathrm{cm}^{2}$, and $73 \%$ were measured in the control device respectively, corresponding to a best conversion efficiency $(\eta)$ of $11.10 \%$. Whereas in the baseline cell structure, i.e., a control cell structure terminated with a p+-CdTe $(\sim 300 \mathrm{~nm}) \mathrm{BCL}$, the $\mathrm{V}_{\mathrm{OC}}$, FF and $\mathrm{J}_{\mathrm{SC}}$ all increased to $0.765 \mathrm{~V}$, $22.8 \mathrm{~mA} / \mathrm{cm}^{2}$ and $78 \%$, respectively, yielding a $\eta$ of $13.60 \%$. By incorporating the $\mathrm{p}+-\mathrm{CdTe}$ layer, $\eta$ increased by $2.5 \%$, confirming previous reports on the benefits of having a heavily As-doped CdTe $\mathrm{BCL}$ in the device structure [5]. However, for the cell with an as-deposited ZnTe:As BCL, a lower $\eta$ of $9.30 \%$ was measured, due to the relatively low $\mathrm{V}_{\mathrm{OC}}$ and FF $(0.627 \mathrm{~V}$ and $64 \%)$, although having a slightly improved JSC of $23.5 \mathrm{~mA} / \mathrm{cm}^{2}$. The improvements in $\mathrm{J}_{\mathrm{SC}}$ observed in both baseline and ZnTe:As contacted CdTe cells was found to be consistent with improved red responses evident in the EQE spectra (Figure $3 b)$. Device series resistance $\left(R_{S}\right)$, on the other hand, improved in baseline and ZnTe:As contacted devices compared to the control sample, possibly indicating the contribution of a heavily doped BCL in reducing the contact resistance to the Au metal contact [6]. Comparing the baseline and ZnTe:As contacted devices, the improvement in $\mathrm{R}_{\mathrm{S}}$ is slightly better in the former, despite the higher conductivity of ZnTe:As, which is expected to yield even lower overall series resistance with the ZnTe:As back contacted devices. The as-deposited ZnTe:As here was not subjected to any post-treatment prior to Au contact application, unlike the $\mathrm{p}+-\mathrm{CdTe}$ in the baseline structure which received the activation anneals along with the CdTe absorber. This could probably be the reason for the slightly higher Rs values observed for the ZnTe:As BCL device. Therefore an appropriate post deposition treatment for the ZnTe:As BCL in the CdTe solar cell structure is expected to further improve device performance. Shunt resistances, $R_{S H}$ greater than $1000 \Omega \cdot \mathrm{cm}^{2}$ were measured for all three devices, which, together with small $\mathrm{R}_{\mathrm{S}}$, contributed to enhancing the devices' FFs, except for the 
device with ZnTe:As BCL. Figure 3c shows the acceptor concentration $\left(N_{\mathrm{A}}\right)$ profiles determined from $\mathrm{C}-\mathrm{V}$ measurements for all three devices. As is evident, $N_{\mathrm{A}}$ for both control and baseline devices are comparable $\left(\sim 1.34 \times 10^{16}\right.$ and $1.0 \times 10^{16} \mathrm{~cm}^{-3}$, respectively), with corresponding narrow depletion widths, whilst for devices with as-deposited ZnTe:As BCL, $N_{\mathrm{A}}$ degrades contrastingly by about one order of magnitude $\left(\sim 1 \times 10^{15} \mathrm{~cm}^{-3}\right)$ with a relatively widened depletion region. These effects seem to suggest that the incorporation of an as-deposited ZnTe BCL to the CdTe cell structure can actually lower the active carrier densities within the junction (depleted) and bulk (non-depleted) regions of the CdTe cell. Comparing the illuminated J-V parameters and $N_{\mathrm{A}}$ profiles, a correlation can be noted between $N_{\mathrm{A}}$ values and the respective $\mathrm{V}_{\mathrm{OC}} \mathrm{s}$ measured for the three device samples. This relationship is consistent with what is generally accepted in the literature, that is, carrier concentration significantly impacts (proportionally) the device $\mathrm{V}_{\mathrm{OC}}$ [19]. Widening of the depletion region, on the other hand, is expected to increase the minority carrier transport to the junction over a larger depth of the absorber, thereby increasing the Jsc and device red response, as experimentally observed.

\subsection{Optimisation of ZnTe:As BCL to CdTe Thin Film Solar Cells}

Cl-Free $\mathrm{H}_{2}$ Annealing

In order to investigate activation of the $\mathrm{ZnTe}$ :As BCL, we performed a series of post-deposition $\mathrm{Cl}$-free $\mathrm{H}_{2}$ anneals on a batch of Glass/ITO/Cd ${ }_{1-x} \mathrm{Zn}_{x} \mathrm{~S} / \mathrm{p}$-CdTe-CHT/ZnTe:As samples. First, we kept the annealing temperature fixed at $420^{\circ} \mathrm{C}$ (i.e., the same annealing temperature for the baseline device activation) and annealed the samples for times ranging from 0 to $30 \mathrm{~min}$. Corresponding illuminated $\mathrm{J}-\mathrm{V}$ curves, EQE spectra and $N_{\mathrm{A}}$ profiles of ZnTe:As back contacted devices, as a function of the $\mathrm{H}_{2}$ annealing times, are summarized in Figure 4.
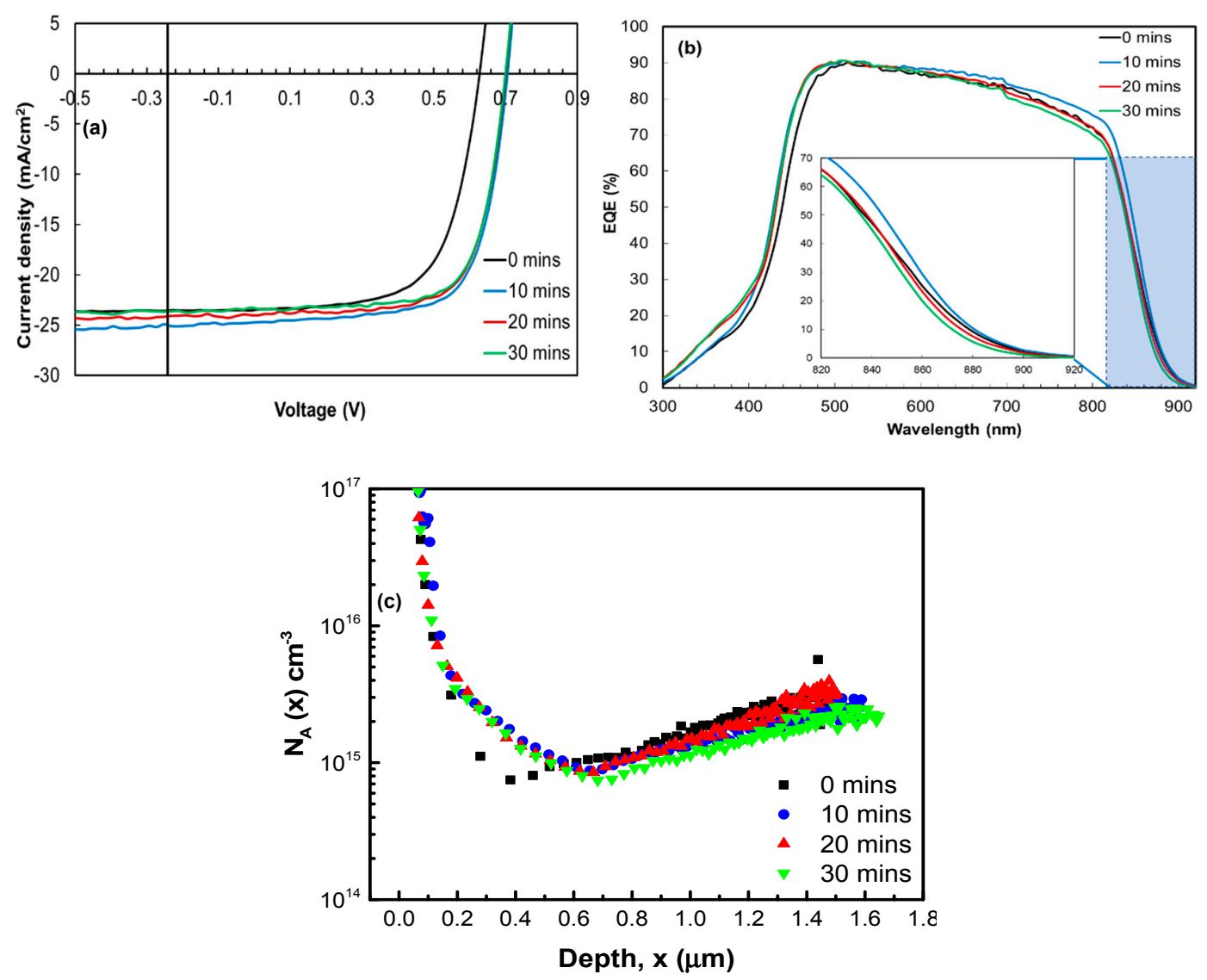

Figure 4. (a) Illuminated J-V curves (b) EQE spectra and (c) acceptor concentration profiles of ZnTe:As back contacted devices annealed at $420^{\circ} \mathrm{C}$ for different times. 
Note that parameters of the device with as-deposited ZnTe:As BCL (see Section 3.2 and Figure 3) is denoted as having received 0 min of annealing in Figure 4, which is considered as the reference device here. Following the $\mathrm{Cl}$-free $\mathrm{H}_{2}$ anneal for $10 \mathrm{~min}$, we see an improvement in the power conversion efficiency $(9.30 \%$ to $12.00 \%)$ primarily due the enhancements in $\mathrm{V}_{\mathrm{OC}}(0.627$ to $0.705 \mathrm{~V})$ and $\mathrm{FF}$ ( $64 \%$ to $69 \%$ ) whilst $\mathrm{JSC}_{\mathrm{SC}}$ remained relatively the same. As for $\mathrm{R}_{\mathrm{S}}$, we also note that by performing the $\mathrm{Cl}$-free $\mathrm{H}_{2}$ anneal, there was a slight improvement in the series resistance compared to our baseline device mentioned in Section 3.2. The significant (2.7\%) efficiency improvement here underscores the significance of ZnTe:As BCL activation and that it appears to be critical to high device performance. For the other samples annealed beyond $10 \mathrm{~min}$ (20 and $30 \mathrm{~min}$ ), no further improvements in FF or $\mathrm{V}_{\mathrm{OC}}$ were seen, instead $\mathrm{J}_{\mathrm{SC}}$ began to degrade slightly, resulting in conversion efficiencies around $11.70 \%$. The loss in JSC was found to correlate well with the EQE spectra (Figure $4 \mathrm{~b}$ ); for longer annealing times above $10 \mathrm{~min}$, the red response slightly degrades. According to the calculated $\mathrm{R}_{\mathrm{SH}}$ and $\mathrm{J}_{0}$ (reverse saturation current density) parameters as a function of annealing time (Table S1), no correlation between the $\mathrm{V}_{\mathrm{OC}}$ and these parameters can be seen. The bulk acceptor concentration in Figure 4c does not appear to improve after annealing for $10 \mathrm{~min}$, but rather remains relatively unchanged with a slight indication of the onset of degradation at higher annealing times (i.e., $30 \mathrm{~min}$ ). Although cell efficiency was enhanced as a result of the $\mathrm{Cl}$-free $\mathrm{H}_{2}$ annealing, extended annealing times greater than $10 \mathrm{~min}$ was not found to be effective in producing any further improvement in the device performance; rather, this was detrimental particularly to the JSC.

Next, we optimised the $\mathrm{Cl}$-free $\mathrm{H}_{2}$ annealing temperature by performing a series of $\mathrm{ZnTe}$ :As BCL post-deposition $\mathrm{Cl}$-free $\mathrm{H}_{2}$ anneals on another batch of samples at higher temperatures; 430, 440, and $450{ }^{\circ} \mathrm{C}$ in addition to the $420^{\circ} \mathrm{C}$ (reference), for a fixed time of $10 \mathrm{~min}$ (optimum time chosen from the data in Figure 4). Figure 5 shows the illuminated J-V curves, EQE spectra, and $N_{\mathrm{A}}$ profiles of $\mathrm{ZnTe}$ :As back contacted CdTe cells following $\mathrm{Cl}$-free $\mathrm{H}_{2}$ anneal at different temperatures. As seen in Figure $5 \mathrm{a}$, devices annealed at $430{ }^{\circ} \mathrm{C}$ yielded similar $\mathrm{J}_{\mathrm{SC}}\left(24.5 \mathrm{~mA} / \mathrm{cm}^{2}\right)$ as those on which a $420^{\circ} \mathrm{C}$ anneal was performed, but deteriorated by about $2-2.3 \mathrm{~mA} / \mathrm{cm}^{2}$ for higher temperature treatments, i.e., 440 and $450{ }^{\circ} \mathrm{C}$. In general, increasing the annealing temperature beyond 420 to $430{ }^{\circ} \mathrm{C}$ for samples in this work did not result in improved device performance, rather the JSC was found to degrade. The bulk acceptor concentration was particularly negatively impacted (Figure 5c) as it reduced with annealing temperature beyond $420{ }^{\circ} \mathrm{C}$. In view of this, we expected a corresponding loss in the respective cell's $\mathrm{V}_{\mathrm{OC}} \mathrm{s}$, according to previous observations, but this was not the case here. The reason for the absence of a correlation between $\mathrm{V}_{\mathrm{OC}}$ and $N_{\mathrm{A}}$ for the different annealing temperatures here is unclear at this stage. Based on the $N_{\mathrm{A}}$ profiles (Figure $5 \mathrm{c}$ ), $420{ }^{\circ} \mathrm{C}$ was chosen as the suitable $\mathrm{Cl}$-free $\mathrm{H}_{2}$ annealing temperature.
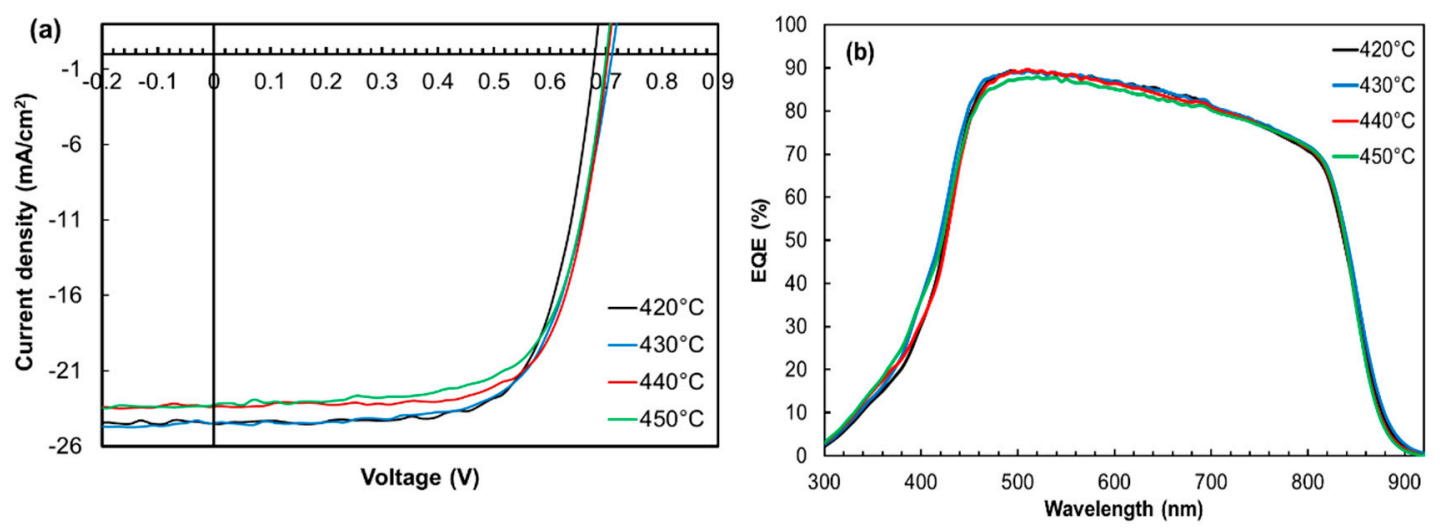

Figure 5. Cont. 


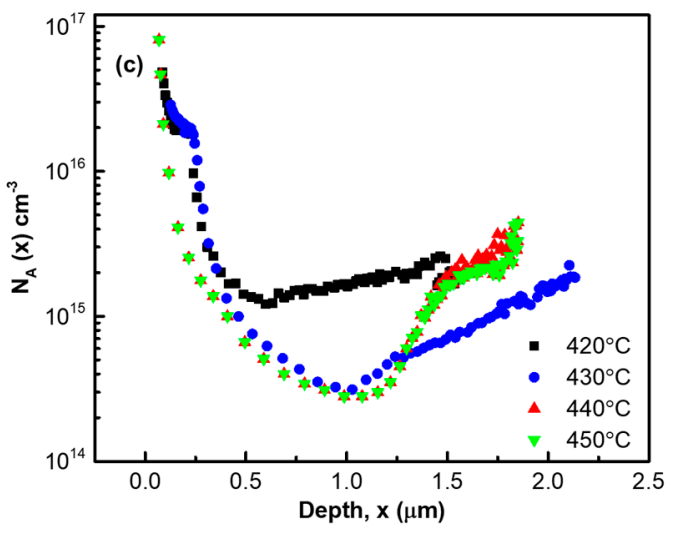

Figure 5. (a) Illuminated J-V curves (b) EQE spectra and (c) acceptor concentration profiles of ZnTe:As back contacted devices annealed at $420,430,440$, and $450{ }^{\circ} \mathrm{C}$ for $10 \mathrm{~min}$ each.

Meanwhile, the XRD patterns of the ZnTe:As BCL on CdTe absorber after $\mathrm{Cl}$-free $\mathrm{H}_{2}$ annealing at 420 and $450{ }^{\circ} \mathrm{C}$ (Figure S3) were obtained to elucidate the impact of annealing temperature on the microstructure of the ZnTe:As back contacted CdTe cells. The sample annealed at $420{ }^{\circ} \mathrm{C}$ showed the ZnTe preferential orientation of (111), as it is consistent with the diffraction peak in the reference ZnTe:As thin film. In the case of the $450{ }^{\circ} \mathrm{C}$ annealed sample, a slight shift in the (111) ZnTe diffraction peak towards (111) CdTe was seen, suggesting microstructural changes and change in $\mathrm{ZnTe}$ composition with $\mathrm{Cd}$ incorporation towards $\mathrm{Zn}$ rich $\mathrm{CdZnTe}$. Comparing with surface SEM images (Figure S4), we observe some coalescence of distinct crystalline structures after annealing at 440 to $450{ }^{\circ} \mathrm{C}$, suggesting that annealing at higher temperatures $\left(>420^{\circ} \mathrm{C}\right)$ is unlikely to be productive for high device performance.

Based on the observations from the foregoing; the $\mathrm{Cl}$-free $\mathrm{H}_{2}$ anneal for $10 \mathrm{~min}$ at $420{ }^{\circ} \mathrm{C}$ is considered as the optimum ZnTe:As BCL post-deposition annealing condition in this work, thus these conditions were employed in all subsequent experiments.

\subsection{ZnTe:As BCL Thickness Optimisation}

We also examined the effect of ZnTe:As BCL thickness and the measured PV parameters of CdTe thin film solar cells with different ZnTe:As BCL thicknesses are summarized in Table 2.

Table 2. PV parameter summary of CdTe thin film solar cells with different ZnTe:As back contact layer thicknesses.

\begin{tabular}{cccccccc}
\hline ZnTe:As $(\mathbf{n m})$ & $\boldsymbol{\eta} \mathbf{( \% )}$ & $\mathrm{JSC}_{\mathbf{S C}}\left(\mathbf{m A} / \mathbf{c m}^{\mathbf{2}}\right)$ & $\mathbf{V}_{\mathbf{O C}}(\mathbf{V})$ & $\mathbf{F F}(\boldsymbol{\%})$ & $\mathbf{R}_{\mathbf{S}}\left(\mathbf{\Omega c m}^{\mathbf{2}}\right)$ & $\mathbf{N}_{\mathbf{A}}\left(\mathbf{c m}^{-\mathbf{3}}\right)$ & $\mathbf{W}_{\mathbf{d}}(\boldsymbol{\mu m})$ \\
\hline 50 & 10.4 & 23.3 & 0.689 & 65 & 5.00 & $1.7 \times 10^{15}$ & 1.01 \\
100 & 11.9 & 23.7 & 0.696 & 72 & 1.45 & $1.9 \times 10^{15}$ & 0.96 \\
200 & 11.8 & 24.1 & 0.691 & 71 & 1.62 & $3.2 \times 10^{15}$ & 0.78 \\
330 & 11.7 & 24.1 & 0.701 & 69 & 1.69 & $2.0 \times 10^{15}$ & 0.81 \\
\hline
\end{tabular}

As seen in Table 2, the device performances are generally similar for BCL thicknesses between 100 and $330 \mathrm{~nm}$. In the case of the $50 \mathrm{~nm}$ BCL, however, a significant drop in efficiency, primarily due to poor FF observed, caused by high $\mathrm{R}_{\mathrm{S}}$, which may result from non-uniform and incomplete coverage of the ZnTe:As layer on the p-CdTe surface [3]. Therefore, to ensure that $\mathrm{p}$-CdTe is completely covered by the ZnTe:As BCL film, the BCL thickness for all remaining samples were kept at nominally $330 \mathrm{~nm}$.

\subsection{Cl-Annealing BCL Post-Deposition Treatments}

Effect of a standard $\mathrm{CdCl}_{2}$ heat treatment, normally applied to CdTe absorbers, is first checked on reference ZnTe:As thin films on glass substrate. The transmittance spectra of reference ZnTe:As thin films, with and without the standard CHT, are shown in Figure 6. Following the CHT, a shift 
in the absorption edge towards longer wavelengths, towards that of $\mathrm{CdTe}$, indicative of $\mathrm{Zn}$ loss and formation of Cd-Te, was observed.

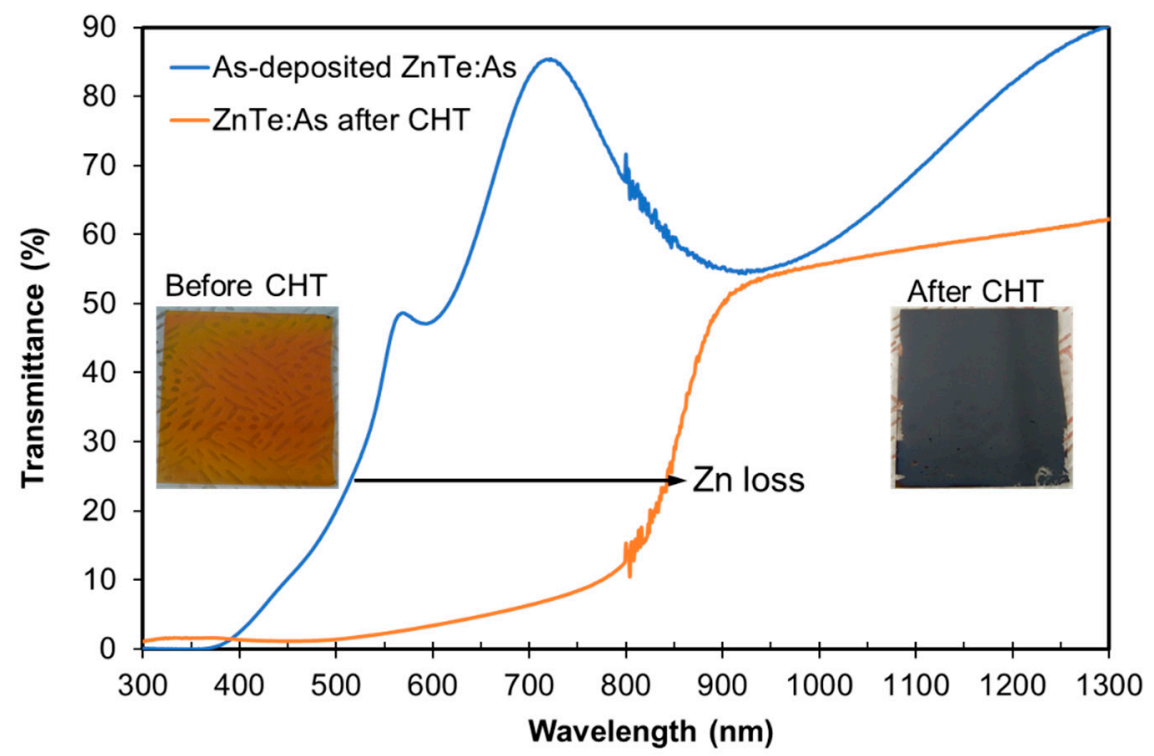

Figure 6. Transmittance spectra and image of a reference thin film of ZnTe:As before and after the standard CHT.

The obvious $\mathrm{Zn}$ loss and formation of $\mathrm{Cd}-\mathrm{Te}$ bonding are believed to be through the formation of highly volatile $\mathrm{ZnCl}_{2}$ during the CHT process [14,15], confirming the difficulty that is expected with performing the standard CHT device activation step following the growth of the ZnTe BCL on the $\mathrm{CdTe}$ absorber. This would eliminate the ZnTe phase from the BCL due to its full conversion to the $\mathrm{CdTe}$ phase. Thus, in order to suppress the $\mathrm{Zn}$ loss in the presence of $\mathrm{Cd}$ precursor, we first attempted a wet $\mathrm{ZnCl}_{2}$ treatment alternative [20], on a sample of as-deposited $\mathrm{ZnTe:As} \mathrm{BCL} \mathrm{device} \mathrm{structure,}$ which resulted in rather poor device performance (results not shown). Thereafter, we also tried to apply the $\mathrm{ZnCl}_{2}$ thin film via MOCVD. However, this proved to be a challenging effort, as the growing $\mathrm{ZnCl}_{2}$ phase was majorly volatile and did not adhere well to the substrate as a thin film coating, thus unlikely to result in an effective $\mathrm{Cl}$ activation of the ZnTe:As BCL.

We then proceeded to assess a milder CHT process for the ZnTe BCL; employing, for the first time, a sacrificial CdS cap layer. This effort was motivated by the work of Shimpi et al [15], who carried out a mild $\mathrm{CdCl}_{2}$ heat treatment and partially activated their $\mathrm{CdZnTe}$ absorbers for thin film solar cells, utilising a thin CdS barrier layer which minimized Zn loss from the CdZnTe phase. The mild CHT approach with a CdS cap was first assessed using reference thin films of ZnTe:As on boro-aluminosilicate glass substrate. Transmittance spectrum of a CdS capped reference ZnTe:As thin film which received a mild CHT indicated a much reduced $\mathrm{Zn}$ loss, indicated by the smaller shift in the absorption edge compared to another film which received the standard CHT with and without the CdS cap (see Figure S5 for details). Under standard CHT conditions, the CdS cap was beneficial in retaining $\mathrm{Zn}$, which was further improved by the mild $\mathrm{CdCl}_{2}$ treatment with a $\mathrm{CdS}$ cap. With this result in mind, we proceeded to evaluate this promising process on the Glass/ITO/Cd ${ }_{1-x} Z_{x} \mathrm{~S} / \mathrm{p}-\mathrm{CdTe}-\mathrm{CHT} / \mathrm{ZnTe}$ :As device structure. We note that the CdS layer was removed by etching before the metallization of the back surface with Au contacts.

Figure 7 shows the illuminated J-V characteristics, EQE spectra, and $N_{\mathrm{A}}$ plots for mild $\mathrm{CdCl}_{2}$-annealed ZnTe:As BCL devices (both with and without the CdS cap layer), as well as a reference device without the additional mild CHT. 

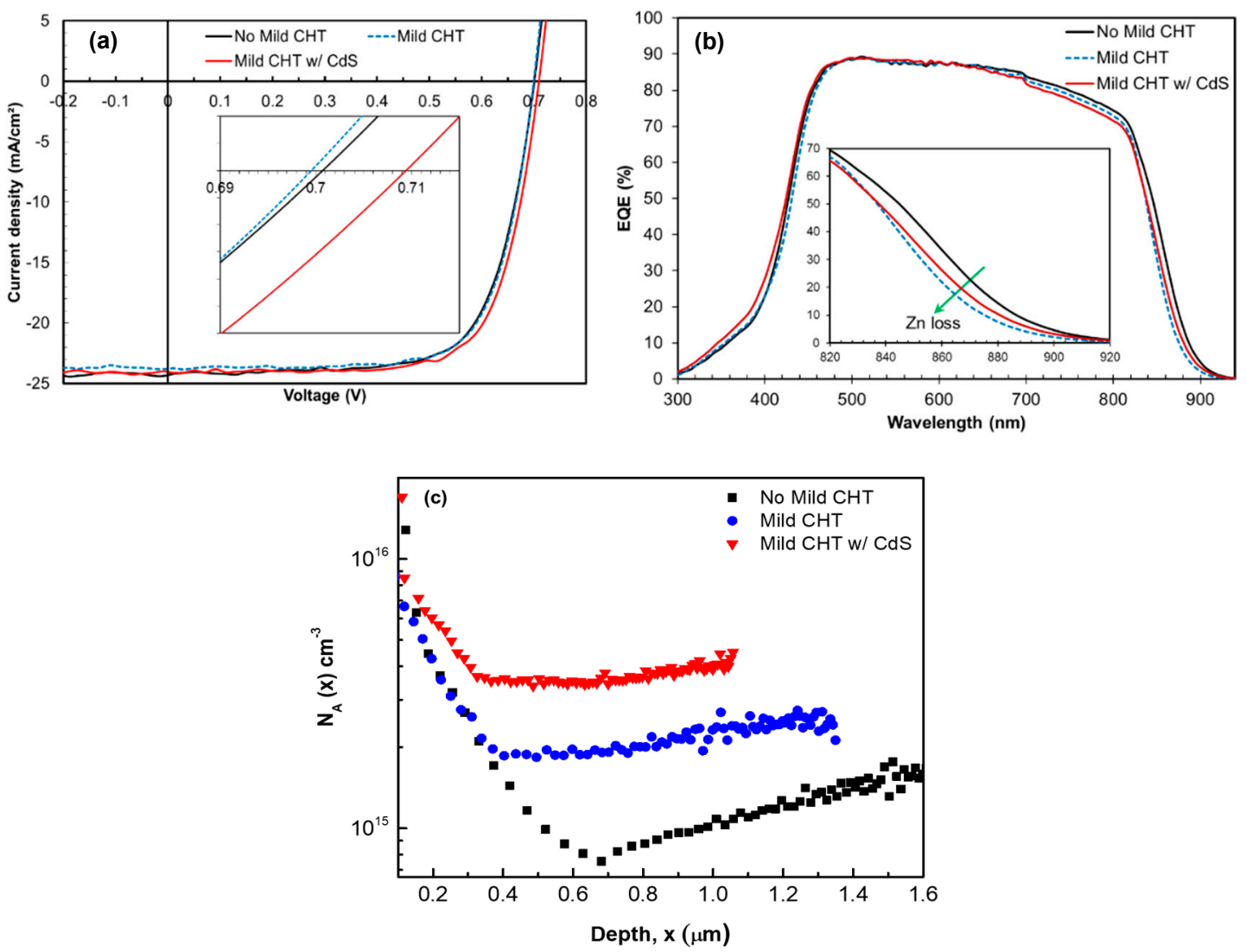

Figure 7. (a) Illuminated J-V curves (b) EQE spectra, and (c) acceptor concentration profiles of ZnTe:As back contacted devices: no mild treatment, with additional mild CHT (with and without CdS cap layer).

Device performances for all three samples are relatively similar, with the best conversion efficiency of $\sim 12.3 \%$ from the device on which a mild CHT was performed on the ZnTe:As BCL with a sacrificial CdS barrier layer present. FF improves slightly from an average of 70.6\% (no mild CHT) to $72.5 \%$ and $72.13 \%$, respectively, for mild CHT devices. However, a slight drop in JSC is observed following the $\mathrm{Cl}$-anneal treatments, with the lowest mean $\mathrm{JSC}_{\mathrm{SC}}$ measured in the sample without a CdS barrier layer during treatment. From EQE spectra in Figure 7b, a good correlation between JSC loss and a declined near-infrared response ( $~ 800-900 \mathrm{~nm}$ region) can be seen, which is attributable to changes in the original ZnTe:As BCL composition following the mild CHT step. Zn loss causes a decline in the near IR response. The sample with the poorest red response correlated well with the device having the lowest $\mathrm{J}_{\mathrm{SC}}$. The changes in this case are particularly connected to $\mathrm{Zn}$ loss. A $\mathrm{V}_{\mathrm{OC}}$ improvement of about $10 \mathrm{mV}$ was also measured in the device which received mild CHT in the presence of a CdS barrier layer. Except for the uncapped $\mathrm{CdCl}_{2}$-annealed sample, which showed a rather slight loss in $\mathrm{V}_{\mathrm{OC}}$, the $\mathrm{V}_{\mathrm{OC}}$ improvement correlates with the $N_{\mathrm{A}}$ determined from C-V measurements (see Figure $7 \mathrm{c}$ ), whereby the acceptor concentration is seen to improve from $\sim 1 \times 10^{15} \mathrm{~cm}^{-3}$ (no mild CHT) up to $\sim 4 \times 10^{15} \mathrm{~cm}^{-3}$ (mild CHT with CdS cap) with corresponding narrowing depletion widths. In Figure 7b, we observe a small increase in the slope of the EQE at long wavelengths for devices on which mild CHT was carried out. This feature has been previously reported for CdTe:As solar cells with varied As doping [11], to be associated with increasing $N_{\mathrm{A}}$, and is consistent with our measured acceptor concentration (see Figure 7c).

ZnTe:As BCL compositional analysis (EDX) shown in Table 3 indicate a 23\% loss in the Zn content (at \%) following the mild CHT without the CdS cap. But this was less in the case of the sample device on which mild CHT was performed with a CdS layer ( $12 \% \mathrm{Zn}$ loss), with an accompanying increase in $\mathrm{Cd}$ at $\%$. 
Table 3. Summary of EDX compositional data from ZnTe:As back contacted region of CdTe cells with and without additional mild $\mathrm{CdCl}_{2}$ heat treatment $(\mathrm{CHT})$.

\begin{tabular}{cccc}
\hline Element & No Mild CHT & Mild CHT & Mild CHT w/CdS \\
\hline Zn (at \%) & 39.0 & 16.3 & 26.5 \\
Cd (at \%) & 4.6 & 31.8 & 24.8 \\
Te (at \%) & 56.4 & 51.9 & 48.8 \\
\hline
\end{tabular}

Figure 8 shows the XRD patterns of ZnTe:As BCL on CdTe thin film structures for the three samples presented in Figure 7 and Table 3. Diffraction peaks close to CdTe $\left(23.98^{\circ}\right)$ [3] can be seen for all samples, which is likely an indication of the preferential orientation along the (111) plane of the underlying $\mathrm{p}$-CdTe layer. The other peak at $25.34^{\circ}$ for the sample without the mild CHT corresponds to the cubic ZnTe (111) reflection [3,18]. For the samples on which a mild CHT was performed (with and without a CdS cap), diffraction peaks can be seen between CdTe (111) and ZnTe (111), identified as belonging to the ternary $\mathrm{Cd}_{1-\mathrm{x}} \mathrm{Zn} \times \mathrm{Te}$ (CZT) [21], which is consistent with the EDX analysis. The double CZT-like diffraction peaks seen in the uncapped mild CHT sample $\left(24.52^{\circ}\right.$ and $\left.24.92^{\circ}\right)$ suggest a bi-layer of CZT structure formed with varying Zn compositions. From Vegard's law it can be predicted that these layers have the compositions 44 and 74 at \%, respectively. Note that composition cannot be determined accurately by EDX data (Table 3) due to interference of $\mathrm{Te}$ and $\mathrm{Cd}$ signals from the underlying CdTe absorber. For the CdS capped mild CHT cell, the CZT layer seems to have formed a graded composition with a dominant $\mathrm{Zn}$-rich region.

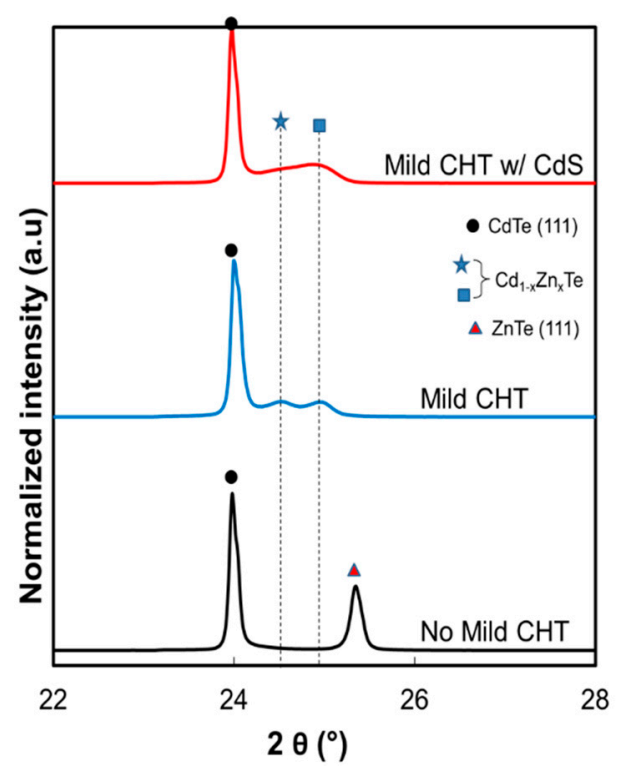

Figure 8. XRD patterns of ZnTe:As back contacted CdTe thin film solar cell structures.

SIMS depth profiles of $\mathrm{Cl}$ in the device samples-no mild CHT, mild CHT (with and without a CdS barrier layer)-are presented in Figure 9. No $\mathrm{Cl}$ loss in the bulk p-CdTe absorber during subsequent ZnTe:As BCL deposition is observed. As expected, $\mathrm{Cl}$ incorporation in the ZnTe:As BCL can be seen following the mild CHT, but less so in the sample without a CdS cap. $\mathrm{Cl}$ accumulation can also be observed around the p-CdTe/ZnTe:As interface for the non-treated device, which is less prominent in the sample which had a CdS barrier during the mild CHT, and almost absent in the case of the uncapped, mild CHT sample. 


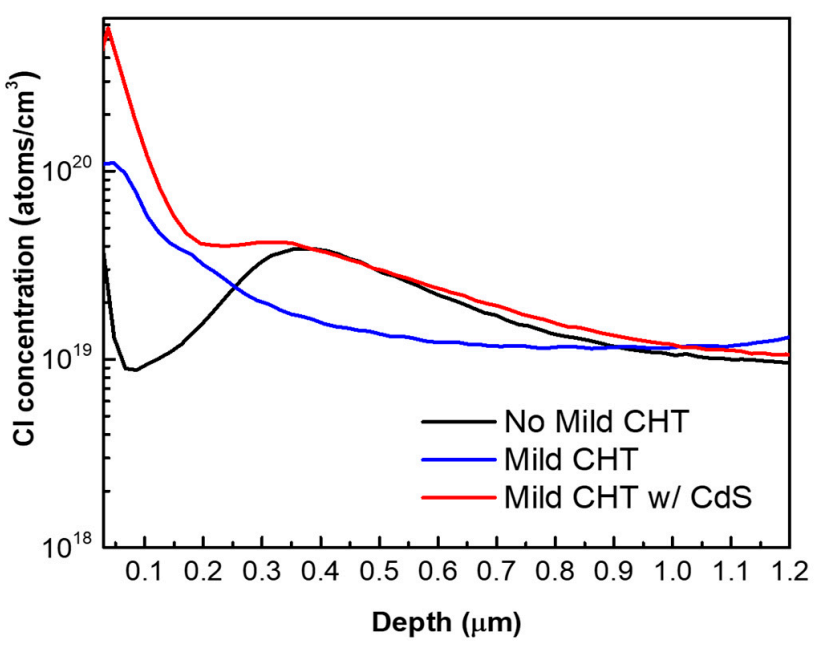

Figure 9. SIMS depth profile of $\mathrm{Cl}$ concentration for ZnTe:As BCL cells having received no mild CHT, mild CHT, and mild CHT with a CdS cap layer.

\section{Discussion}

It is clear from Table 1 that reasonably high doping concentrations can be achieved in px ZnTe via in-situ As doping with MOVCD. Such bulk carrier concentrations demonstrated here for ZnTe:As, compares well with reported values for single crystal p-ZnTe [12,13]. Following device incorporation, the as-deposited ZnTe:As back contacted CdTe solar cell performed rather poorly compared to control and baseline device structures. Despite the JSC enhancement (compared to control and baseline cells), the loss in the $\mathrm{V}_{\mathrm{OC}}$ and FF was responsible for the poorer performance of the ZnTe:As BCL device. $\mathrm{V}_{\mathrm{OC}}$ deterioration appeared to be correlated with an order of magnitude loss in absorber carrier density $\left(N_{\mathrm{A}}\right)$. The sharp drop in $N_{\mathrm{A}}$ is believed to be the culprit, as it significantly impacts $\mathrm{V}_{\mathrm{OC}}$ [19]. We are uncertain as to the origin of the decade loss in $N_{\mathrm{A}}$ following ZnTe:As BCL incorporation; however, a number of probable factors are worth taking into consideration. Interface contamination is one of such factors: following $\mathrm{CdCl}_{2}$ heat treatment post-deposition of a p-CdTe bulk absorber, the device structure was removed from the MOCVD reactor and excess $\mathrm{Cl}$ rinsed prior to reintroducing it back in the reactor for ZnTe:As BCL growth. The possible surface contamination acquired during the process may produce additional surface defects, and recombination sites, contributing to reduction in some device parameters [14]. Another important factor is the large lattice mismatch ( $5.8 \%)$ between CdTe and ZnTe:As [3]. It is believed that this could lead to interface states and enhance recombination losses. If the minority carriers (electrons) are reflected back to CdTe from the energetically higher positioned $\mathrm{ZnTe}$ conduction band, these carriers can readily recombine via these interface states.

By performing the $\mathrm{Cl}$-free $\mathrm{H}_{2}$ anneal $\left(420^{\circ} \mathrm{C}\right.$, for $\left.10 \mathrm{~min}\right)$ post $\mathrm{ZnTe}$ :As BCL deposition, minor recovery of $N_{\mathrm{A}}$ can be seen (Figure $4 \mathrm{c}$ ). Although slight as it may appear, the physical origin of this thermally induced recovery is yet unknown. However, according to Wolden and co-workers [22], interface state passivation from interdiffusion at $\mathrm{p}-\mathrm{CdTe} / \mathrm{ZnTe}$ :As interfaces could partly be responsible for the observed recovery in the acceptor concentration. This phenomenon and other factors could also be at work in the case of the secondary mild $\mathrm{CdCl}_{2}$-anneal treatment post $\mathrm{BCL}$ deposition (with and without a CdS barrier layer; see Figure 7c). Additionally, the mild CHT induced conversion of ZnTe to $\mathrm{Cd}_{1-\mathrm{x}} \mathrm{Zn}_{\mathrm{x}} \mathrm{Te}$ compositions, inferred from transmittance and XRD results (Figure S5 and Figure 8), is expected to minimise the strain between the ZnTe BCL and the p-CdTe layer and improve the interface quality. This is expected because $\mathrm{Cd}_{1-\mathrm{x}} \mathrm{Zn}_{\mathrm{x}} \mathrm{Te}$ has a smaller lattice mismatch to $\mathrm{CdTe}$ compared to ZnTe [3]. Consequently, this could result in eliminating some interface defect states responsible for the degradation of $N_{\mathrm{A}}$ through recombination losses.

Note also that during the ZnTe:As BCL deposition at $370{ }^{\circ} \mathrm{C}$ and subsequent device anneals performed to improve the $\mathrm{BCL}$, the $\mathrm{CdTe}$ absorber can be considered as undergoing additional post 
annealing which could restructure it by overtreatment. According to Abbas et al [23] post annealing of $\mathrm{CdS} / \mathrm{CdTe}$ devices can result in $\mathrm{Cl}$ removal from absorber grain boundaries and the re-emergence of stacking faults, consequently detrimental to device performance. As discussed above (in relation to Figure 9) we do not see $\mathrm{Cl}$ loss from bulk or the back surface region of the absorber. Additionally, the performance was observed to be enhanced following the $\mathrm{Cl}$-free $\mathrm{H}_{2}$ annealing as well as the mild CHT performed on our samples. Therefore, $\mathrm{Cl}$ loss related effects due to post annealing does not play a significant role for our devices.

\section{Conclusions}

In summary, we have investigated polycrystalline ZnTe:As back contacts to CdTe thin film solar cells grown by MOCVD. Highly conductive px ZnTe:As thin films with p-type carrier concentration as high as $4 \times 10^{18} \mathrm{~cm}^{-3}$ by in-situ As doping, appropriate for back contact use in CdTe thin film solar cells, was achieved. Although, a slight improvement in JSC was measured in as-deposited ZnTe:As back contacted devices, both $\mathrm{V}_{\mathrm{OC}}$ and FF degraded, largely owing to a loss in absorber acceptor concentration $\left(\mathrm{N}_{\mathrm{A}}\right)$. A (Cl-free) $\mathrm{H}_{2}$ anneal carried out following ZnTe:As BCL deposition at optimum conditions $\left(420^{\circ} \mathrm{C}\right.$ and $10 \mathrm{~min}$ ) induced some minor recovery in $N_{\mathrm{A}}$ and $\mathrm{V}_{\mathrm{OC}}$ and improvement to $\mathrm{BCL}$ crystallinity, indicating the need for a suitable ZnTe:As BCL post-deposition (activation) treatment, which is critical to device performance. When the standard (relatively aggressive) $\mathrm{CdCl}_{2}$ heat treatment, applied to activate the CdTe cell, was performed post ZnTe:As BCL deposition, then full conversion of $\mathrm{ZnTe}$ was observed into the CdTe phase due to the formation of volatile $\mathrm{ZnCl}_{2}$.

A milder $\mathrm{CdCl}_{2}$-anneal treatment investigated using a thin CdS cap on the $\mathrm{ZnTe}$ surface (as a sacrificial barrier layer) caused an appreciable enhancement in the $N_{\mathrm{A}}$ and mitigated $\mathrm{Zn}$ loss. About $10 \mathrm{mV}$ improvement in the $\mathrm{V}_{\mathrm{OC}}$ was measured in devices which received the additional mild CHT with the CdS cap compared to untreated and non-capped mild CHT reference devices. Although some $\mathrm{Zn}$ loss was still noted with the use of a sacrificial barrier layer on the ZnTe surface, the concept showed promise towards full activation of the ZnTe:As BCL, without excessive $\mathrm{Zn}$ depletion and loss of $N_{\mathrm{A}}$. Mild CHT on the ZnTe film with a CdS cap was seen to be the most effective approach leading to $N_{\mathrm{A}}$ recovery in this study. Acceptor concentration recovery is considered to be largely due to $\mathrm{p}-\mathrm{CdTe} / \mathrm{ZnTe}$ :As interface improvement. Additionally, a slight reduction of lattice mismatch is implied from the resulting $\mathrm{Cd}_{1-\mathrm{x}} \mathrm{Zn}_{\mathrm{x}} \mathrm{Te}$ formation following mild CHT with a CdS cap. To further minimise $\mathrm{Zn}$ loss, other materials such as $\mathrm{Al}_{2} \mathrm{O}_{3}$ as an alternative to $\mathrm{CdS}$ [24] could be investigated. Additionally, direct deposition of the ternary alloy $\mathrm{Cd}_{1-\mathrm{x}} \mathrm{Zn}_{\mathrm{x}} \mathrm{Te}$, which has an intermediate lattice mismatch (less than ZnTe) to CdTe, can be studied as an interlayer between p-CdTe and ZnTe:As.

Supplementary Materials: The following are available online at http://www.mdpi.com/1996-1944/12/22/3706/s1, Figure S1: Transmittance spectra of ZnTe thin films with different amounts of As; Figure S2: Comparison between XRD patterns of ZnTe thin films on boro-aluminosilicate glass substrate; undoped $(0 \mathrm{sccm})$ and doped with As (10 sccm); Figure S3: XRD patterns of ZnTe:As reference film, ZnTe:As back contacted CdTe thin films annealed at $420^{\circ} \mathrm{C}$ and $450{ }^{\circ} \mathrm{C}$; Figure S4: SEM of surface images of ZnTe:As BCL after different heat treatments; Figure S5: Transmittance spectra of reference thin films of as deposited ZnTe:As before and after standard CHT (with and without CdS sacrificial layer) and ZnTe:As after mild CHT with CdS sacrificial layer

Author Contributions: Conceptualization, G.K.; methodology, G.K. and O.O.; investigation, O.O. and G.K.; data curation, G.K. and O.O.; writing—original draft preparation, O.O.; writing-review and editing, G.K., S.J.C.I. and O.O.; supervision, G.K.; project administration, G.K.; funding acquisition, S.J.C.I. and G.K.

Funding: This research was funded by the 2nd Solar Photovoltaic Academic Research Consortium (SPARC II) and the SIZETSOLAR project.

Acknowledgments: The authors would like to acknowledge the European Regional Development Fund (ERDF) and the Welsh European Funding Office (WEFO) for funding the 2nd Solar Photovoltaic Academic Research Consortium (SPARC II) and the SIZETSOLAR project supported by the British Council which supported this research.

Conflicts of Interest: The authors declare no conflict of interest. 


\section{References}

1. Green, M.A.; Emery, K.; Hishikawa, Y.; Warta, W.; Dunlop, E.D. Solar cell efficiency tables (version 50). Prog. Photovolt. Res. Appl. 2017, 25, 668-676. [CrossRef]

2. Lourenço, M.A.; Yew, Y.K.; Homewood, K.P.; Durose, K.; Richter, H.; Bonnet, D. Deep level transient spectroscopy of CdS/CdTe thin film solar cells. J. Appl. Phys. 1997, 82, 1423-1426. [CrossRef]

3. Amin, N.; Yamada, A.; Konagai, M. Effect of ZnTe and CdZnTe Alloys at the Back Contact of 1- $\mu$ m-Thick CdTe Thin Film Solar Cells. Jpn. J. Appl. Phys. 2002, 41, 2834-2841. [CrossRef]

4. Bätzner, D.L.; Romeo, A.; Zogg, H.; Wendt, R.; Tiwari, A.N. Development of efficient and stable back contacts on CdTe/CdS solar cells. Thin Solid Films 2001, 387, 151-154. [CrossRef]

5. Irvine, S.J.C.; Barrioz, V.; Lamb, D.; Jones, E.W.; Rowlands-Jones, R.L. MOCVD of thin film photovoltaic solar cells-Next generation production technology? J. Cryst. Growth 2008, 330, 5198-5203. [CrossRef]

6. Späth, B.; Fritsche, J.; Klein, A.; Jaegermann, W. Nitrogen doping of ZnTe and its influence on CdTe/ZnTe interfaces. Appl. Phys. Lett. 2007, 90, 062112. [CrossRef]

7. Li, J.; Beach, J.D.; Wolden, C.A. Rapid Thermal Processing of ZnTe:Cu Contacted CdTe Solar Cells. In Proceedings of the 40th IEEE Photovoltaic Specialist Conference, Denver, CO, USA, 8-13 June 2014; pp. 2360-2365.

8. Uliĉnâ, S.; Isherwood, P.J.M.; Kaminski, P.M.; Walls, J.M.; Li, J.; Wolden, C.A. Development of ZnTe as back contact material for thin film cadmium telluride solar cells. Vacuum 2016, 139, 159-163. [CrossRef]

9. Amin, N.; Yamada, A.; Konagai, M. ZnTe Insertion at the Back Contact of $1 \mu \mathrm{m}-\mathrm{CdTe}$ Thin Film Solar Cells. In Proceedings of the 28th IEEE Photovoltaic Specialists Conference, Anchorage, AK, USA, 15-22 September 2000; pp. 650-653.

10. Makhratchev, K.; Price, K.J.; Ma, X.; Simmons, D.A.; Drayton, J.; Ludwig, K.; Gupta, A.; Bohn, R.G.; Compaan, A.D. ZnTe:N Back Contacts to CdS/CdTe Solar Cells. In Proceedings of the 28th IEEE Photovoltaic Specialists Conference, Anchorage, AK, USA, 15-22 September 2000; pp. 475-478.

11. Kartopu, G.; Oklobia, O.; Turkay, D.; Diercks, D.R.; Gorman, B.P.; Barrioz, V.; Campbell, S.; Major, J.D.; Al Turkestani, M.K.; Yerci, S.; et al. Study of thin film poly-crystalline CdTe solar cells presenting high acceptor concentrations achieved by in-situ arsenic doping. Sol. Energy Mater. Sol. Cells 2019, 194, $259-267$. [CrossRef]

12. Kamata, A.; Yoshida, H. Highly conductive p-type ZnTe: As grown by atmospheric metalorganic chemical vapor deposition using Trimethylarsine. Jpn. J. Appl. Phys. 1996, 35, CL87-CL89. [CrossRef]

13. Turco-Sandroff, F.S.; Brasil, M.J.S.P.; Nahory, R.E.; Martin, R.J.; Zhang, T.; Skromme, B.J. Arsenic-doped P-type ZnTe grown by molecular beam epitaxy. Appl. Phys. Lett. 1991, 59, 688-690. [CrossRef]

14. Mohanty, D.; Su, P.-Y.; Wang, G.-C.; Lu, T.-M.; Bhat, I.B. Effect of $\mathrm{CdCl}_{2}$ treatment on $\mathrm{ZnTe}$ back electron reflector layer in thin film CdTe solar cells. Sol. Energy 2016, 135, 209-214. [CrossRef]

15. Shimpi, T.M.; Swanson, D.E.; Drayton, J.; Abbas, A.; Walls, J.M.; Barth, K.L.; Sampath, W.S. CdS barrier to minimize $\mathrm{Zn}$ loss during $\mathrm{CdCl}_{2}$ treatment of $\mathrm{Cd}-\mathrm{Zn}-\mathrm{Te}$ absorbers. Sol. Energy 2018, 173, 1181-1188. [CrossRef]

16. Kartopu, G.; Philips, L.J.; Barrioz, V.; Irvine, S.J.C.; Tejedor, E.; Dupin, D.; Clayton, A.J.; Rugen-Hankey, S.L.; Durose, K. Progression of metalorganic chemical vapour-deposited CdTe thin-film PV devices towards modules. Prog. Photovolt. Res. Appl. 2016, 283-291. [CrossRef]

17. Becker, J.J.; Campbell, C.M.; Zhao, Y.; Boccard, M.; Mohanty, D.; Lassise, M.; Suarez, E.; Bhat, I.; Holman, Z.C.; Zhang, Y.-H. Monocrystalline CdTe/MgCdTe Double-Heterostructure Solar Cells with ZnTe Hole Contacts. IEEE J. Photovolt. 2017, 7, 307-312. [CrossRef]

18. Shimpi, T.M.; Drayton, J.; Swanson, D.E.; Sampath, W.S. Properties of Nitrogen-doped Zinc Telluride Films for Back Contact to Cadmium Telluride Photovoltaics. J. Electron. Mater. 2017, 46, 5112-5120. [CrossRef]

19. Okamoto, T.; Yamada, A.; Konagai, M. Characterization of Highly Efficient CdTe Thin Film Solar Cells by the Capacitance-Voltage Profiling Technique. Jpn. J. Appl. Phys. 2000, 39, 2587-2588. [CrossRef]

20. Maniscalo, B.; Abbas, A.; Bowers, J.W.; Kaminski, P.M.; Bass, K.; West, G.; Walls, J.M. The activation of thin film CdTe solar cells using alternative chlorine containing compounds. Thin Film Solids 2015, 582, 115-119. [CrossRef] 
21. Tobin, S.P.; Norton, P.W.; Chandler-Horowitz, D.; Amirtharaj, P.M.; Lope, V.C.; Duncan, W.M.; Syllaios, A.J.; Ard, C.K.; Giles, N.C.; Lee, J.; et al. A Comparison of Techniques for Nondestructive Composition Measurements in CdZnTe Substrates. J. Electron. Mater. 1995, 24, 697-705. [CrossRef]

22. Wolden, C.A.; Abbas, A.; Li, J.; Diercks, D.R.; Meysing, D.M.; Ohno, T.R.; Beach, J.D.; Barnes, T.M.; Walls, J.M. The roles of ZnTe buffer layers on CdTe solar cell performance. Sol. Energy Mater. Sol. Cells 2016, 147, $203-210$. [CrossRef]

23. Abbas, A.; West, G.D.; Bowers, J.W.; Kaminski, P.M.; Maniscalco, B.; Walls, J.M.; Barth, K.L.; Sampath, W.S. Cadmium Chloride Assisted Re-Crystallisation of CdTe: The Effect of Annealing Over-Treatment. In Proceedings of the IEEE 40th Photovoltaic Specialist Conference (PVSC), Denver, CO, USA; 2014; pp. 701-706.

24. Reich, C.L.; Swanson, D.E.; Onno, A.; Shimpi, T.; Metzger, W.K.; Sampath, W.S.; Holman, Z.C. Alloy Loss Mitigation Through Use of Barrier Layers During CdCl2 Processing of $\mathrm{Cd}_{0.60} \mathrm{Zn}_{0.4} \mathrm{Te}$ and $\mathrm{Cd}_{0.87} \mathrm{Mg}_{0.13} \mathrm{Te}$. In Proceedings of the IEEE 7th World Conference on Photovoltaic Energy Conversion (WCPEC), Waikoloa, HI, USA, 10-15 June 2018.

(C) 2019 by the authors. Licensee MDPI, Basel, Switzerland. This article is an open access article distributed under the terms and conditions of the Creative Commons Attribution (CC BY) license (http://creativecommons.org/licenses/by/4.0/). 